\title{
Blood-Feud - Internally Displacing Because of Life Security Threat
}

\author{
MA. Edlira Baka Peco \\ University of Tirana (Albania) - Faculty of Social Sciences \\ edlira.baka@unitir.edu.al,edabaka@gmail.com
}

\section{Doi:10.5901/mjss.2014.v5n4p509}

\begin{abstract}
Trying to keep away a social problem, by migrating physically from it. This seems to be the 'deal' that many Albanian families have opted for, as an opportunity in the last two decades. The general trend of migrating from North to the Central part of the country aiming to escape a threat has been the common action in escaping a conflict. Bloodfeud pheonomenon as a pattern that migrates along with the displaced families; its effects and consequences in the todays' transitional Albania. The transformaiton of a social problem from a sub cultural norm to an obstacle to start a different and safe life in dignity into a new settlement - the suburbs of urban areas.
\end{abstract}

Keywords: internal migration, bloodfeud, subcultural norms.

\section{Introduction}

Nowadays blood feud is defined as a serious social plague in the Albanian society. While for quite some decades it stood not active, sleepy and somehow away from the society awareness, the alarming figures of the last ten years seem to have produced an impact caused mostly by the accumulated attitudes of persons ivovled in such phenomenon. Blood feuds all but disappeared in Albania during the 40-year rule of Enver Hoxha, the Communist dictator who outlawed the practice, sometimes burying those who disobeyed alive in the coffins of their victims. However legal experts in Albania say that the feuds erupted again after the fall of Communism ushered in a new period of lawlessness. ${ }^{1}$ Blood feuds in Albania are often said to be regulated by the so-called Kanun of Leke Dukagjini, which can be defined as: "a meticulous blueprint governing all aspects of community life, with rules set in place for everything from how to bury the dead and conduct a proper wedding to what happens when one person's bee swarm ventures onto another's property" (The New York Times Magazine 26 Dec. 1999, 33).

Nevertheless in fact still today it can be easily assessed that from different points of view it is quite difficult to distinguish a genuine act that is attributed to the Kanun and the "traditional " blood feuds acts and those that are undertaken based on criminal elements who hide their intentions and reasoning of committing those actions under the norms and the values of the code they claim to belong to. (The Sydney Morning Herald 7 Aug. 1999; ICG 1 Mar. 2000; Schwandner-Sievers 13 Feb. 1999).

This reasearch paper will aim at explaining what happens from the social cultural point of view, to those cases that are under the pressure and the surveillance of blood feud, mostly those who decide to be displaced because of the fear of persecution due to the threat of life by a non -state agent, indirectly also by a state that seems partly unwilling and partly uncapable in defending the fundamental human right: safe life in dignity. It seems that big cities have become in the last two decades the refuge for many of the blood feud victims. They are placed in the suburbs, in the remoted areas of abandoned neighbourhoods while many others have fled abroad and sought asylum due to their claim of being in life threat.

Albania is more and more aware and concerned of having a phenomeon spread up all over the country and recently our neighbous, but not only are faced with the challenge to offer and ensure safe protection to these individuals, families, groups. Blood feuds, or vendettas are being used and referred randomly as the consequences of a series of applicable norms and values that although are crossed through generations in a very strange and dangerous way, are

\footnotetext{
${ }^{1}$ Although the phenomenon has declined in recent years, blood feuds continue to deprive families of basic human rights, a report of the Albania's Ombudsman 2012, underlines: pp.17. According to the Ombudsman's report, there were 98 murders due to vendettas from 2001 to 2012, including five in the first nine months of the last year. "Murders due to blood feuds account for 34.4 per cent of the murders that have occurred in Albania in the past two decades,"
} 
being transformed in a common threat, are putting in risk the lives of men and of women, of elderly and unfortunately of children too.

\section{Literature Review}

For the sake of the research of this paper and analysis it comprises the phenonomenon of blood feued will be seen in a cross-cut dimesnion with migration phenomenon. Due to the fact that the research on this topic has been undertaken within the territory of Albania, the internal displacement /migration will constitute the focus of this analysis. The internal migratory flows in Albania are due to several factors, i.e. economic situation, and security reasons in the cases of blood feud and risk of, or actual, trafficking of women and children. Internal migrants in Albania are confronted with huge social and economic problems. As a result of significant internal migration, thousands of citizens no longer have local registration and status, which has led to a loss of access to basic services such as education and medical care. The situation of those displaced for security reasons within Albania is particularly serious, given the lack of capacity (in the case of blood feud) and/or of commitment or even outright complicity (in the case of trafficking in persons) by state actors, notably the State Police. The governmental responsibility in preventing and addressing the causes of internal displacement still remains a task ahead.

The blood feud is often confused with blood revenge, what in practice, both operate on the same 'rules', but the blood feud refers to the Kanun and it is mainly active in north and central Albania, while the blood revenge does not refer to any institutional body2.

\subsection{Availability of state protection}

The State admits the phenomenon and to some extent has implicitly acknowledged the impossibility of the State authorities to protect the families threatened by these phenomena ${ }^{3}$. In the beginning of years 2000 , the then Minister of Public Order ${ }^{4}$ admitted that the blood feud is one of the motivations for the most crimes of murder, and speaks about: 'a reduce of crimes of blood vengeance killing, compared to prior periods'. There are several reports in which state officials have been targeted for blood feud. Because of the lack of state protection, tens of policemen were secluded because of blood feud; i.e. the Chairman of the Municipal Council in Shkodra, was secluded, meanwhile in order to continue the work of the Municipality - everyday, the secretary used to bring to his home the documents that had to be signed, all because a nephew of his, committed a murder in London, United Kingdom. The efforts for state intervention have been needed and somehow noticed in the recent years. A thorough gap analysis on the legal, institutional and practical point of view has been conducted and actions for improvement have been tried based on this working tool ${ }^{5}$.

Considering the right to life as the most fundamental and important right of individual protected by law and recognizing the risk of blood feud on affecting this right (homicides, house confinements and deprivation of other rights and freedoms), in 2012 the People's Advocate took the initiative to raise the awareness of state institutions, civil society and the individuals regarding this sensible issue. According to statistics of the General State Directorate, during the first nine months of 2012, five murders occurred because of blood feud, whereas the People's Advocate finds out that there was a positive movement in 2012 by the state bodies in this regard. In addition to the public acceptance of such phenomenon, state bodies have started to take concrete measures such as: establishment of the inter-ministerial working group for the preparation and approval by the Council of Ministers of three legal acts pursuant to and in

\footnotetext{
2 The Kanun regulates the blood feud rules, its beginning and end. The Kanun was transmitted orally for generations, and it served as a foundation of social behavior and self-government for the clans of Northern Albania for more than five centuries (it was collected and put in writing during the first quarter of the 20th century). The importance of the Kanun in the history of the Albanian people can scarcely be overestimated, and its precepts continue to exert a significant influence on a significant number of Albanian families living in Albania, Kosovo, Montenegro, Macedonia, as well as in other countries to which Albanians have emigrated. KANUN, Periodical magazine for Human Rights, no. 2, 2000 - 2001

${ }^{3}$ Several Ministries, such as the Ministry of Public Order, Education, Foreign Affairs etc, have granted the status and rights to the AllNational Reconciliation Mission: Decision of District Court Shkoder, On the registration of the All-National Reconciliation Association, date 17.05.1995; Authorization from the Ministry of Public Order, date 06.07.1999, Ministry of Justice, date 31.08.1999; Ministry y of Education, date 22.07.1998.

${ }_{4}^{4}$ KANUN, Periodical magazine for Human Rights, no. 2, 2000 - 2001.

5 The Albanian Parliament has approved up to present a number of laws and ratified different international treaties. Of special importance was the Law no. 9389, dated 4 May 2005 "On the creation and functioning of the Coordinating Council in the fight against Blood feud".
} 
implementation of Law no. 9389, dated 04.05.2005 "On the Establishment and Operation of the Coordinating Council in the Fight against Blood Feud". But, in addition to such measures, there is a need for the immediate enforcement of the relevant law and for a close cooperation and coordination between the central and local government structures to face such complicated phenomenon. "Blood Feud" is still one of the worrying phenomena in the Shkodra region and unfortunately not only. Its effects are widely being evidenced throughout the whole country and through international migration also in neighboring countries and overseas. Governmental institutions try to pay special attention to the activities aimed at raising the awareness of the public and competent authorities, in order to say "Stop" to this occurrence.

\subsection{Situation and risk of children with regard to the blood feud}

The rights of the children locked/secluded inside their homes from fear of blood feud killing have been increasingly at the focus a series of studies and policies nation-wide.

Many Albanian families have been displaced within or outside the country because of the fear of being killed in the chain of feuds in the regions they were born or living in. Due to ongoing vendettas, hundreds of children are forced to stay at home, or to hide with their families, and are unable to attend school or other activities of social and cultural life. According to the reports more than 200 children of 9-15 years old do not attend the school in the North of Albania, each academic year due to the blood feud phenomenon, involving their parents/families ${ }^{7}$. Many families have been displaced within or abroad the country, because of the fear of being killed in the chain of feuds in the regions they were born or are living. Due to ongoing vendettas, hundreds of children are forced to stay at home, or to hide with their families, and are unable to attend school or other activities of social and cultural life. Around 5,000 people in Albania are somehow affected by blood feud killings - revenge killings by a victim's family against the killer's family, more than 600 of them are children ${ }^{8}$. According to the Sunday Telegraph, more than 20,000 people "live under an ever-present death sentence" due to blood feuds (National Reconciliation Committee - 3 June 2007). In a letter to the Commissioner for Human Rights in Europe, the National Reconciliation Committee Chair states that 9,500 lives have been claimed by self-justice in 17 years (National Reconciliation Committee - 1 Nov. 2007). A 21 June 2006 document on the National Reconciliation Committee website states that 5,000 lives were claimed by self-justice in 15 years. A 2004 article on the University College London website states that, in 2001, blood feuds caused roughly 73 percent of violent deaths in Albania.

Although the blood feud phenomenon dates back to the Middle Ages, many of the "rules" have unfortunately, not been adapted to modern times. The killing of women and children is prohibited, but still most are yet forced to go into hiding or remain closed in at home. In May 2012, a 14 years old girl was killed because of blood feud. Making matters worse, the practice of vendetta has spread from the north of the country to the cities and southern rural areas. In a bid to educate these "trapped" children, the Ministry of Education and Sciences has launched a programme called "Second Chance" but it barely works due to public funds limitations by the state authorities to the teachers and the continuous displacement of affected families.

In this analysis of the phenomenon in the suburbs of the Albanian capital, Tirana, will be reviewed and discussed few issues that are related to the migration due to the blood feud. While the causes are extensively noted all around the country and not only, the consequences and the impacts of those displaced because of the blood feuds vary at a specific level, making their situation distinctive from the rest of the arrivals in the area.

\section{Research Methodology}

The analysis included in this paper there has been followed an empirical technique of the quantitative research methods. Indeed this analysis is only a part of whole doctoral study on the integration of the internally displaced persons in the suburbs of Tirana, (Albanian capital). Blood feud is among those social grazes that have forced many of the inhabitants of Albanian peripheries to be populated chaotically and most of all in unsecured premises for their lives and well-beings. There have been involved in such research 868 individuals, a sample chosen randomly in a population of 15,000 people of Bathore periphery. The questionnaire applied had five sections that made a total 45 questions. The questioning tool

\footnotetext{
6 "On the activity of the People's Advocate 1st January - 31st December 2012" [page 18-19]

7 Ibid - as above

${ }^{8}$ United Nations High Commissioner for Refugees Confidential Comments Committee on the Rights of the Child 61st Session 17 September - 5 October 2012 [pp.23]
} 
took almost 20-30 minutes per each sample to be completed and was a self-administered methodology. The data gathered as result of such field survey were processed in SPSS 16.0 and the database provided a series of findings and relevant results also in the framework of people approach and behaviour towards the cause of blood feud as the stimulating factor of migrating internally in the country.

\subsection{The operationalisation of general concepts}

For the purpose of this analysis I had to operationalise the concepts treated in this study. There were two major variables treated; migration and blood feud. In a causal relation each of them changes the relevance depending on the point of discussion. Operationalisation of these two concepts is the practical specification of the range that each of the phenomena represents itself. As result the theoretical models that will be applicable in the targeted area will have to be operational because as such are also the social facts from which the argumentation and the application has started. The aim of this paper is not to fix any conceptual entity, be that of migration or of the blood feud. The value of each of the variables becomes sociologically interesting when it can be potentially used to predict the attributes that will allow the interaction between the studied subjects in a targeted and pre-defined area.

Migration, for the sake of this analysis has been operationalise in its internal framework, while blood feud is contextualised in urban areas under the pressure of inherited norms and seen in a socio-cultural perspective.

\subsection{Bathore - Case Study}

Geographically, the region of Bathore consists a total surface is 14 square $\mathrm{km}$, just $16 \mathrm{~km}$ away from the centre of the capital - Tirana. Population is estimated 20,000 inhabitants, but matter-of-factly, considering the growth trends and those unregistered by the office this figure is higher. The absolute density is 1,000 inhabitants per square $\mathrm{km}$, and $35 \%$ of total population belongs to the age group 0 - 15 years old, that is, almost $1 / 3$ of the total. In Bathore neighbourhood, part of Kamza town there live nearly $1 / 3$ of the total population. The average number of persons per household is 6,5 . Bathore is now a vivid example of the coexistence of an enough heterogeneous population. Breakdown of population by sex shows a male - female ratio of $52: 48$ in percentages ${ }^{9}$.

\subsection{Survey techniques}

868 individuals were asked for a period of three months in 2012 on the reasons, effects, problems, concerns and experiences of internal migration, trying to explore and reflect interpretations on their integration in the new premises of residence. Many of them had a history of more than 20 years of migration but typically were noticed individuals that touched upon the migration phenomenon both at a national and international point of view..$^{10}$

The area under focus was still in quite remote conditions which made the survey techniques a bit more complex and difficult than the usual. A local inhabitant of the area assisted in many of the meetings and contacts with the individuals approached. Separate interviews and informal meetings were conducted for the sake of a better understanding of all the patterns of the daily life of the area under monitoring.

In addition three interviews with the Mayor of Kamza (city having under its jurisdiction Bathore neighbourhood), a journalist and an historian part of the local community were conducted as qualitative material to emphasize the verification of the study hypothesis; the socio-cultural integration of the internal migrants in the area of Bathore is still in the apprentice level due to the norms and values inherited by the origin sub-cultures.

\section{Findings and Review}

As appears by the below percentages (Table 1) one of the principal reasons that has determined the decision of fleeing the previous residence and the settlement in the suburbs of a city such as Tirana ${ }^{11}$ is escaping from conflicts or other incidental problems/ blood feud and risk of revenge. A percentage of 27.4 of the total sample has opted for this answer.

\footnotetext{
9 United Nations Economic Commission for Europe/ http://www.unece.org/fileadmin/DAM/h/m/prgm/cph/experts/albania/materials /kamza.pdf [pp 1-4]

${ }^{10} 22 \%$ of the sample answered to have at leats on relative or to have been personally at least once emigrant.

11 Population of Tirana, as per the CENSUS 2011, is 749,365 people http://www.instat.gov.al/media/178070/rezultatet_kryesore_t _censusit_t_popullsis_dhe_banesave_2011_n_shqip_ri.pdf
} 
Most of the questioned persons, part of this group are previous residents of North of the country, originating mostly from rural areas such as Puke, Malesi e Madhe, Shkoder and Has. The settlement of this category into the new neighbourhood has consequently faced additional challenges in comparison to the rest of the groups that have come randomly in the same period of time 1993-1996.

Table 1:

\begin{tabular}{|l|l|c|}
\hline \multicolumn{2}{|c|}{ Question Answer/Alternatives } & Data in \% \\
\hline $\begin{array}{l}\text { Why have you displaced/fled } \\
\text { from the previous } \\
\text { residence/town and came to live } \\
\text { here? }\end{array}$ & For a better climate & $1.3 \%$ \\
\cline { 2 - 3 } & $\begin{array}{l}\text { For reasons related to personal health conditions or those to a family } \\
\text { member }\end{array}$ & $1.2 \%$ \\
\cline { 2 - 3 } & For a better life & $22.4 \%$ \\
\cline { 2 - 3 } & To be near to relatives and siblings & $9.7 \%$ \\
\cline { 2 - 3 } & The city offers more employment opportunities & $29.7 \%$ \\
\cline { 2 - 3 } & The city offers better education chances for the children & $2.3 \%$ \\
\cline { 2 - 3 } & To escape from conflicts or other incidental problems/ blood feud, revenge & $\mathbf{2 7 . 4 \%}$ \\
\cline { 2 - 3 } & Others & $6.0 \%$ \\
\cline { 2 - 3 } & Total & $100.0 \%$ \\
\hline
\end{tabular}

There are a series of relevant and interesting sociological facts that accompany the integration process of these people, individually and family wise. A staring point of their raison d'etre is the fear from the perpetrator, a risk that goes along with them on the daily life, for all the members of the family regardless to their gender and age. For many of them the fear is perceived at different levels. The ultimate decision upon transforming of this fear from a small risk to a real persecution, results very often in international migration act. Such decision is justified by the concerned people in two dimensions; escape from the immediate risk, personally and the rest of the family members, and second be able to support economically the family while abroad.

This kind of choice not always functions at the best positive consequence but it is foremost seen as the escape from the immediate risk.

In 2000, a young Albanian man was playing with a loaded weapon and accidentally shot and killed his best friend. The perpetrator (the young man) fled and claimed refugee status in West London (UK). People in the local Albanian community in West London determined the identity of the perpetrator and reported back to people in Albania that the perpetrator was residing in West London. Then, in June 2002, the rival Albanian family (the brother and cousin of the deceased) smuggled themselves into the UK and, with no intention of staying permanently, claimed asylum. While in the UK, they determined the perpetrator's location and in September 2002, murdered him. The brother and cousin chose the method of stabbing to carry out the killing. The use of stabbing is significant because it conveys a sense of dishonour for a victim. An honourable opponent is shot with a gun. (Standish. A. 2008: 23)12.

The fear stays in the newly populated areas not only among the $27,4 \%$ of those directly involved in blood feud phenomenon. The whole group of interviewed people answer this way (Table 2) on the three most problematic concerns in the new habitation.

Table 2:

List three of the most problematic concerns you are faced in the area you are living?

\begin{tabular}{|l|c|}
$\begin{array}{l}\text { 1. Poverty } \\
\text { 2. Infrastructural problems } \\
\text { 3. Threats from previous conflicts or incidents from the places of origin }\end{array}$ & $70.2 \%$ \\
\hline $\begin{array}{l}\text { 1. Uncertainty on employment } \\
\text { 2. Threats from previous conflicts or incidents from the places of origin } \\
\text { 3. Infrastructural problems }\end{array}$ & $16.8 \%$ \\
\hline $\begin{array}{l}\text { 1. Threats from previous conflicts } \\
\text { 2. Corruption } \\
\text { 3. Lack of adequate education standards }\end{array}$ & $10.8 \%$ \\
\hline Others & $2.2 \%$ \\
\hline No answer & $0.0 \%$ \\
\hline Total & $100.0 \%$ \\
\hline
\end{tabular}

12 Albania Blood Feuds - Paper 2008 http://www.ecoi.net/file_upload/1684_1243258524_http-www2-irb-cisr-gc-ca-en-researchpublications-index-e-htm.pdf 
Regardless of the internal or international migration, the fact of displacement brings with itself a series of other steps that relate to the development of the concept of living, individual and social behaviours as well as interactions and intersocialisation between the people themselves and the communities in which they settle. Among the $27.4 \%$ of the total individuals asked, at least half of them declared to have noticed a series of improvements in their daily life thanks to the migration in the suburbs of the city. Although many of them mentioned the fear and uncertain circumstances of living due to the involvement in blood feud, still the engagement in to collective work places, the functioning of the public education institutions for the new generation as well the presence of the state police much near to the habitation has marked a level of at least $43 \%$ of living improvement. In such improvement are included features such as: incomes, tolerance and harmony in heterogeneous populated areas, social and entertainment life and offering of services at local and central level.

Indeed one of the measurable indicators of the integration of this community in the area are the daily activities and the style of arranging and engaging in the daily life. While many of the youngsters of Bathore area, study or work in Tirana (city) many others of an elder age, identify them as part of the new habitation although many of the norms and actions they undertake in their daily style of living seem more similar to the previous subcultures from which they originate rather than of those in Tirana. While $22.1 \%$ of the sample answer to have in their present houses 'çifteli' ("double stringed" musical tool - taken and inherited by their previous habitations) only $0.3 \%$ assess to have a gun in their homes. Consequently from the $22.1 \%$ possessing a 'çifteli', only almost half of them accept to have learned the new generation how to play it, while many more than $0.3 \%$ possessing a gun or not, accept to have used and/or know how to use such fire weapon.

Most of them assess that such attitude and situation is attributed, among other factors also to the fear of previous blood feuds or potential conflicts that might occur. Table 3 shows the reaction towards the conflict in the newly inhabited area. Even though many of them have almost two decades that live in the suburbs of urban premises the fear of conflict and the probable resolution of that stands wither on self-condemnation or support by siblings and relatives of the extended family.

Table 3:

\begin{tabular}{|l|c|}
\hline \begin{tabular}{|} 
Which way would you choose to resolve a problem in case you are involved in \\
a conflict or injustice act?
\end{tabular} & Percentage \\
\hline I would deposit a formal claim to the state authorities & $1.9 \%$ \\
\hline I would go for court procedures & $5.2 \%$ \\
\hline I would publish the problem through the local or national medias & $3.1 \%$ \\
\hline I would seek help and support from friends or relatives & $87.8 \%$ \\
\hline No answer & $2.9 \%$ \\
\hline Total & 100.0 \\
\hline
\end{tabular}

\section{Concluding Remarks}

It seems obvious that the social and psychological drama that these people carry with them even though more than two decades have already passed has inevitably brought the blood feud scene in the suburbs of Tirana, although the norms and values of the Kanun are not typical for this part of the country. More concerning appears the situation when children are not allowed or facilitated to attend the schools, even in the newly inhabited area. Such phenomenon brings additional priorities for the community, local authorities sand civil society. The economic and political transition has been transformed in a very complex terrain of transformation of social and psychological values.

Generations are escorting in time, throughout the years and in space from one place/location to another a series of messages that carry within themselves not only history but also culture. Many of those that claim and assess to have reached considerable levels of integration in the settlement area in the suburbs of Tirana, in the backstage of their lives have either the threat of blood feud or the fear that it might become threatening companion of their urban life. While they try to abandon some archaic rituals of the sub-cultures they are coming from, certain features of a conservative nature seem to persecute them even in the 21 century. Such features seem to be opaque and immune even towards the interventions, laws and policies state tries to take. With a keen and impartial eye of a social researcher Standish assesses that it is extremely difficult to resolve blood feuds third party, usually an elder, can be approached by families in blood and asked to organize a reconciliation meeting. Although this seems a ritual taken as a practice long ago, similar scenes are being seen in the peripheries of big cities even nowadays. Individuals and representatives of the family that 
has incurred blood can attend this meeting under a trust (besa). The reconciliation meeting takes place on neutral territory. Big cities seem to be the suitable terrain for such scene. Each side of the blood feud gives its account of events and, through the mediator, tries to broker a settlement (Standish. A., 2007: 19).

The urban style and the internal migration seem to have shaped the various typical behaviours and rituals of many migrants in the suburbs of big cities. Although they tent to preserve many values of their subcultures, certain norms and rules; not necessarily positive, seem to be embedded in their way and path of living, sense of interaction among themselves and the community, even though in their conscience they are obviously fighting against them.

In many societies there are various culturally legitimised forms of behaviour dedicated to the resolution of conflicts, the settlement of disputes and the allocation of responsibility. They are often the principal means by which disputes are settled, conflict resolved and the moral fabric of the community maintained (White 1998,p. 188). When mediation seem not to be effective, then migration enters as a substituting tool of regularising the situation. The Albanian community bares similar characteristics to many other Balkan countries, approaches in a high context culture where honour is one of the most valued norms in the society and is carried out as a belonging in every settlement the individual or his/her family is displaced.

\section{References}

Standish, A. (2008) Issue Paper - Albania Blood Feuds

Rodina M. 1999 "Blood Code Rules in Northern Albania."

Deutsche Presse-Agentur (DPA). 11 March 2000. BC Cycle. "Albanian Blood Feuds Affect 210,000, Many Trapped In Their Homes." (NEXIS)

International Crisis Group. 1 March 2000. Albania: State of the Nation.

The New York Times Magazine. 26 December 1999. Scott Anderson. "The Curse of Blood and Vengeance."

Schwandner-Sievers, S. (1999). Arenas of Power in Conflict: Between 'Reform' and 'Tradition'. Paper presented at the Albanian Studies Day "Custom and Law in a Time of Transition, School of Slavonic and East European Studies, University of London.

Marjorie, M., (1999) The Sydney Morning Herald "Albania. Ancient Legal Code Fuels Surge in Vendetta Killings."

United Nations High Commissioner for Refugees Confidential Comments Committee on the Rights of the Child 61st Session 17 September - 5 October 2012 [pp.23] 